\title{
Hormonal circadian rhythms in patients with congenital adrenal hyperplasia: identifying optimal monitoring times and novel disease biomarkers
}

\author{
Miguel Debono ${ }^{1,4}$, Ashwini Mallappa', Verena Gounden', Aikaterini A Nella ${ }^{2}$, \\ Robert F Harrison ${ }^{3}$, Christopher A Crutchfield ${ }^{2}$, Peter S Backlund ${ }^{2}$, Steven J Soldin' ${ }^{1}$, \\ Richard J Ross ${ }^{4}$ and Deborah P Merke ${ }^{1,2}$ \\ ${ }^{1}$ National Institutes of Health Clinical Center, Building 10, Room 1-2742, 10 Center Drive, Bethesda, Maryland 20892, \\ USA ${ }^{2}$ The Eunice Kennedy Shriver National Institute of Child Health and Human Development, Bethesda, Maryland, \\ USA, ${ }^{3}$ Department of Automatic Control and Systems Engineering, University of Sheffield, Sheffield, UK and \\ ${ }^{4}$ Academic Unit of Endocrinology, University of Sheffield, Sheffield, UK
}

\author{
Correspondence \\ should be addressed \\ to M Debono \\ Email \\ m.debono@sheffield.ac.uk
}

\begin{abstract}
Objectives: The treatment goal in congenital adrenal hyperplasia ( $\mathrm{CAH}$ ) is to replace glucocorticoids while avoiding androgen excess and iatrogenic Cushing's syndrome. However, there is no consensus on how to monitor disease control. Our main objectives were to evaluate hormonal circadian rhythms and use these profiles to identify optimal monitoring times and novel disease biomarkers in $\mathrm{CAH}$ adults on intermediate- and long-acting glucocorticoids.

Design: This was an observational, cross-sectional study at the National Institutes of Health Clinical Center in 16 patients with classic $\mathrm{CAH}$.

Methods: Twenty-four-hour serum sampling for $\mathrm{ACTH}, 17$-hydroxyprogesterone (17OHP), androstenedione $\left(\mathrm{A}_{4}\right)$, androsterone, DHEA, testosterone, progesterone and 24-h urinary pdiol and 5 $\beta$-pdiol was carried out. Bayesian spectral analysis and cosinor analysis were performed to detect circadian rhythmicity. The number of hours to minimal ( $\left.T_{\text {min }} A C\right)$ and maximal $\left(T_{\max } A C\right)$ adrenocortical hormone levels after dose administration was calculated.

Results: A significant rhythm was confirmed for ACTH $\left(r^{2}, 0.95 ; P<0.001\right), 170 H P\left(r^{2}, 0.70 ; P=0.003\right)$, androstenedione $\left(r^{2}, 0.47 ; P=0.043\right)$, androsterone $\left(r^{2}, 0.80 ; P<0.001\right)$, testosterone $\left(r^{2}, 0.47 ; P=0.042\right)$ and progesterone $\left(r^{2}, 0.64 ; P=0.006\right)$. The mean (s.D.) $T_{\min } \mathrm{AC}$ and $T_{\max } \mathrm{AC}$ for $17 \mathrm{OHP}$ and $\mathrm{A}_{4}$ were: morning prednisone (4.3 (2.3) and 9.7 (3.5) h), evening prednisone (4.5 (2.0) and $10.3(2.4) \mathrm{h})$, and daily dexamethasone (9.2 (3.5) and 16.4 (7.2) h). AUC $0-24 \mathrm{~h}$ progesterone, androsterone and 24-h urine pdiol were significantly related to $170 \mathrm{HP}$.

Conclusion: In CAH patients, adrenal androgens exhibit circadian rhythms influenced by glucocorticoid replacement. Measurement of adrenocortical hormones and interpretation of results should take into account the type of glucocorticoid and time of dose administration. Progesterone and backdoor metabolites may provide alternative disease biomarkers.
\end{abstract}

\section{Introduction}

Congenital adrenal hyperplasia is an autosomal recessive condition which in $95 \%$ of patients is caused by 21-hydroxylase deficiency, an enzyme of the cytochrome P450 family essential for cortisol and aldosterone biosynthesis (1). This enzyme defect results in cortisol deficiency, which by impaired negative feedback on the hypothalamicpituitary-adrenal axis, stimulates corticotropin (ACTH) synthesis. ACTH secretion is regulated by circadian input from the central clock in the suprachiasmatic nucleus and follows a circadian pattern with an early morning rise, (c) 2015 European Society of Endocrinology Printed in Great Britain
Published by Bioscientifica Ltd. 
reaching a peak in the morning on waking, and slowly declining towards an evening nadir (2). In untreated or most treated CAH patients, this rhythm is maintained and adrenal androgens, which are also under the influence of $\mathrm{ACTH}$, are released in a circadian pattern resulting in hyperandrogenism and its clinical consequences $(3,4,5)$.

Patients with $\mathrm{CAH}$ suffer from multiple morbidities related to excess androgens or glucocorticoid over-replacement. Thus, the challenge for the endocrinologist is to achieve a balance between these two undesirable states. Endocrine Society guidelines have recommended the use of hydrocortisone in children whereas up to two-thirds of adults are commonly receiving intermediate and long-acting glucocorticoids $(1,6)$. A number of strategies have been suggested to help guide dose titration, such as measuring 17-hydroxyprogesterone (17OHP) and androstenedione before the early morning hydrocortisone dose in an attempt to measure peak hormone levels $(7,8)$. No definite criteria exist as to what time in relation to dose administration this should be performed in patients on intermediate- and longacting glucocorticoids. Synthetic glucocorticoids have diverse pharmacokinetic characteristics with wide interindividual variability and unpredictable effects on rhythm parameters and hormone concentrations $(9,10)$, making it problematic for physicians to decide on dose changes when measuring random hormone levels.

We measured hormonal circadian rhythms of $\mathrm{CAH}$ patients on intermediate- and long-acting glucocorticoids. In addition to routinely measured hormones, we analyzed profiles of progesterone, DHEA, the precursor to pregnanetriol, $5 \beta$-pregnane- $3 \alpha, 17 \alpha$-diol-20-one (5 $\beta$-pdiol), and the backdoor pathway metabolites androsterone (also a classic pathway product) and $5 \alpha$-pregnane- $3 \alpha, 17 \alpha$-diol20-one (pdiol) (11) (Figure 1). The use of multiple hormone levels at different time points provided us with a robust measurement of 24-h hormone exposure as opposed to a single random hormone concentration as usually performed in clinical care. Our goal was to evaluate hormonal diurnal rhythms in patients with $\mathrm{CAH}$, which then allowed us to determine optimal monitoring time ranges for identifying hormonal suppression and escape from hormonal control, and explore novel disease biomarkers.

\section{Patients and methods}

\section{Study patients}

An observational, cross sectional study was carried out at the National Institutes of Health Clinical Center, Bethesda, MD. Sixteen patients with classic 21-hydroxylase deficiency (five simple virilizing; 11 salt wasting) participated. This 24 -h serial sampling study was performed as part of the baseline visit of two clinical trials investigating the use of circadian hydrocortisone replacement (www. clinicaltrials.gov identifier no. NCT01735617 and NCT01859312) and patients were receiving their usual at home medication regimen. The diagnosis of $\mathrm{CAH}$ was ascertained using medical records and hormonal tests and confirmed by genotype (12). Five patients were on a daily dexamethasone dose (dose range: $0.25-0.5 \mathrm{mg}$, in hydrocortisone equivalent $(\times 80)^{7} 9.6-21.3 \mathrm{mg} / \mathrm{m}^{2}$ per day). Four of these patients were taking dexamethasone in the evening whereas one patient was taking dexamethasone in the morning. Eleven patients were on twice daily prednisone (dose range: $2-7.5 \mathrm{mg}(\mathrm{am}), 2-5 \mathrm{mg}(\mathrm{pm})$ in hydrocortisone equivalent $(\times 5)^{7}: 12.0-33.7 \mathrm{mg} / \mathrm{m}^{2}$ per day. All patients were on a stable glucocorticoid regimen for a 3 month minimum. Other inclusion criteria included age 18 years and over, plasma renin activity $<1.5$ times the upper normal range and a negative pregnancy test. Patients who were taking medications that induce hepatic enzymes or interfere with glucocorticoid metabolism, spironolactone, inhaled, oral or nasal glucocorticoids apart from treatment for $\mathrm{CAH}$, or had taken estrogen-containing oral contraceptive pill within 6 weeks of recruitment were excluded. Patients with clinical or biochemical evidence of hepatic, renal or psychiatric disease, were also excluded. The study was approved by the Eunice Kennedy Shriver National Institutes of Child Health and Development (NICHD) Institutional Review Board and all patients gave their written informed consent.

\section{Study design}

All participants were admitted overnight and blood was sampled from an i.v. cannula every $2 \mathrm{~h}(2300 \mathrm{~h}$ until $2300 \mathrm{~h}$ ). Patients continued to take their usual medications during sampling. The following hormones were measured: ACTH, androstenedione, 17OHP, androsterone, DHEA, testosterone and progesterone. Glucocorticoid levels (dexamethasone, prednisolone) were also measured. In addition, a $24 \mathrm{~h}$ urine sample, timed from $2300 \mathrm{~h}$ on Day 1 to $2300 \mathrm{~h}$ on Day 2, was collected to measure the backdoor metabolite pdiol and the precursor to pregnanetriol, $5 \beta$-pdiol (Fig. 1).

\section{Assays}

Hormones were analysed at the NIH Clinical Center (Bethesda, MD, USA) unless otherwise noted. 


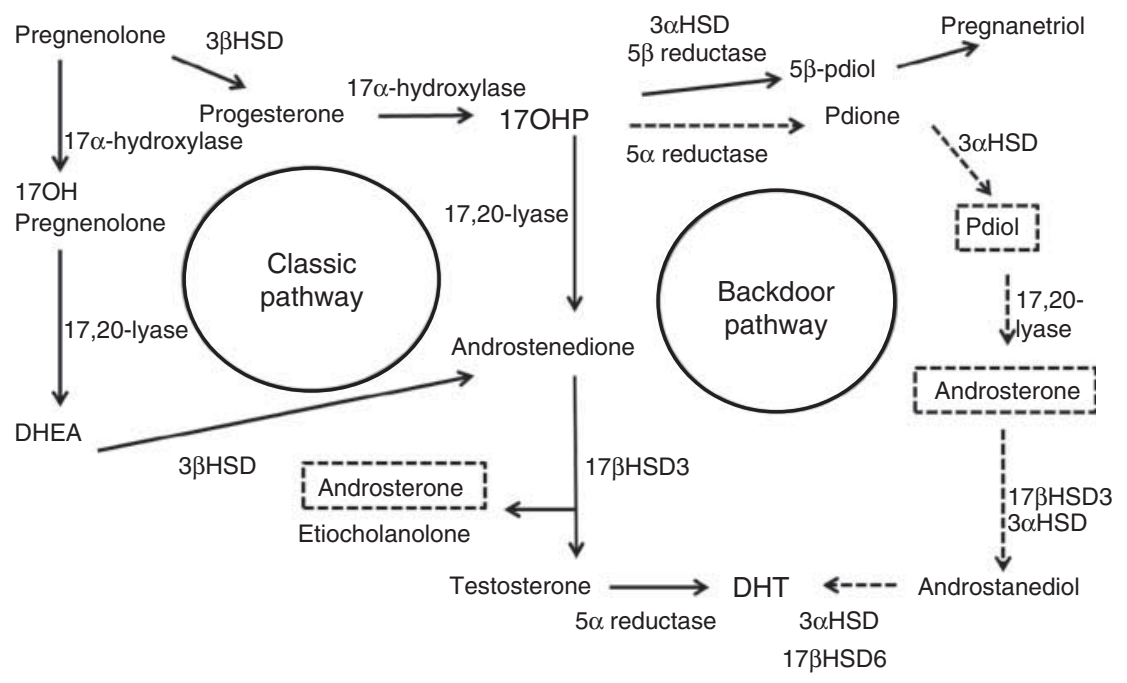

\section{Figure 1}

Pathway of adrenal steroidogenesis. Normally, the principal route for adrenocortical androgen production is via the classic pathway (solid line arrows). In 21-hydroxylase deficiency, large amounts of 170HP are converted to androstenedione via this classic pathway and these are the common biomarkers used in $\mathrm{CAH}$ to estimate disease control. Accumulating 170HP can also

Androstenedione, 17OHP, androsterone, DHEA, testosterone and progesterone were measured by liquid chromatography-tandem mass spectrometry (LC-MS/MS) $(13,14)$. Within-day coefficient of variation (CV) ranged from 2.4 to $9.5 \%$ and between-day CV from 3.0 to $9.9 \%$. An Agilent 6490 triple-quadrupole mass spectrometer coupled with an Atmospheric Pressure Photoionization (APPI) source and Agilent 1200 Infinity series HPLC were used employing isotope dilution with deuterium labeled internal standard for each analyze. Instrument parameters were as follows: gas temperature $325^{\circ} \mathrm{C}$, vaporizer $400{ }^{\circ} \mathrm{C}$, gas flow of $11 \mathrm{l} / \mathrm{min}$, nebulizer $60 \mathrm{psi}$, and capillary $4000 \mathrm{~V}$.

Urinary pdiol and $5 \beta$-pdiol were determined by LC-ESI-MS/MS (NICHD Biomedical Mass Spectrometry Facility, Bethesda, MD, USA). Briefly, $1 \mathrm{ml}$ aliquots of urine were treated with $\beta$-glucuronidase (Type VII-A, Sigma), followed by addition of an internal standard $\left({ }^{13} \mathrm{C}(3)\right.$ 17-hydroxyprogesterone). Steroids were then isolated by solid-phase weak anion exchange using DPXWAX tips (DPX-Labs), eluted with isopropanol/5\% ammonium hydroxide, and dried by vacuum centrifugation. The dried samples were dissolved in $0.2 \mathrm{ml}$ isopropanol:water (1:1) (v/v) and analyzed by LC/MS/MS, using an Agilent 6460 QQQ mass spectrometer. Steroids were separated by reversed phase chromatography using be converted to pdione via an alternative route termed the backdoor pathway (dotted arrows). Androsterone is produced by both the classic and backdoor pathways. The end product for both pathways is ultimately dihydrotestosterone (DHT), the most potent androgen receptor agonist.

an Acquity UPLC BEH C18 (2.1 I.D. $\times 150 \mathrm{~mm}$ ) column, and eluted with a linear gradient from $100 \% \mathrm{~A}$ (water/0.1\% formic acid) to $30 \%$ B (isopropanol/0.1\% formic acid). Pdiol and 5 $\beta$-pdiol concentrations were determined by an MRM assay. The precursor ion (MH$\left.2\left(\mathrm{H}_{2} \mathrm{O}\right)\right)+(\mathrm{m} / \mathrm{z} 299)$ was selected and product ions 161 , 147,135 were followed. Concentrations were determined from peak ratios of the pdiol or $5 \beta$-pdiol to the internal standard and standard curves generated by the addition of steroid standards to a stripped urine matrix. A linear response was obtained for levels up to $1500 \mathrm{pmol} / \mathrm{ml}$ (correlation coefficient $>0.997$ ). Sensitivity was $\sim 1 \mathrm{pmol} / \mathrm{ml}$ for either pdiol or $5 \beta$-pdiol and betweenday $\mathrm{CV}$ were from 4 to $12 \%$. The minimum concentration of pdiol and 5 $\beta$-pdiol for $\mathrm{CAH}$ patients was 3 and $20 \mathrm{pmol} / \mathrm{ml}$ respectively (median pdiol $=230 \mathrm{pmol} / \mathrm{ml}$ and $5 \beta-$ pdiol $=1600 \mathrm{pmol} / \mathrm{ml})$. Total urinary excretion of pdiol and $5 \beta$-pdiol per $24 \mathrm{~h}$ was calculated from steroid concentration and the 24-h urine volume for each patient.

Plasma ACTH was measured using a chemiluminescence immunoassay on Siemens Immulite 2000 XPi analyzer (NIH Clinical Center) with sensitivity of $1.1 \mathrm{pmol} / \mathrm{l}$, and intra- and inter-assay CV 2.5 and 3.6\% respectively. Dexamethasone and prednisolone were analyzed by LC-MS/MS (Mayo Medical Laboratories, 
Rochester, MN, USA) with a sensitivity of 2.5 and $2.8 \mathrm{nmol} / \mathrm{l}$ respectively. For prednisolone and dexamethasone intra-assay $\mathrm{CV}$ were 4.9 and $6.1 \%$ at 33 and $31 \mathrm{nmol} / \mathrm{l}$, respectively, whereas inter-assay $\mathrm{CV}$ were 8.6 and $9.3 \%$ at 324 and $8 \mathrm{nmol} / \mathrm{l}$. The following conversion values for normal ranges were used: ACTH (1.1-10.1 pmol/l; pg/ml 0.22); $17 \mathrm{OHP}(0.4-5.3 \mathrm{nmol} / \mathrm{l}$; $\left.\mathrm{ng} / \mathrm{dl}^{*} 0.0303\right) ;$ androstenedione $\left(0.6-6.1 \mathrm{nmol} / \mathrm{l} ; \mathrm{ng} / \mathrm{dl}{ }^{*}\right.$ $0.0349)$; androsterone $\left(0.7-2.8 \mathrm{nmol} / \mathrm{l} ; \mathrm{ng} / \mathrm{dl}^{*} 0.0349\right)$; DHEA $\left(0.8-20.8 \mathrm{nmol} / \mathrm{l} ; \mathrm{ng} / \mathrm{dl}^{*} 0.0347\right) ;$ testosterone male $\left(3.5-25.7 \mathrm{nmol} / \mathrm{l} ; \mathrm{ng} / \mathrm{dl}^{*} 0.0347\right) ;$ testosterone female $\left(0.3-2.5 \mathrm{nmol} / \mathrm{l} ; \mathrm{ng} / \mathrm{dl}^{*} 0.0347\right)$; progesterone male (0.03-0.2 nmol/l; $\left.\mathrm{ng} / \mathrm{ml}^{\star} 3.18\right)$; progesterone female $(0.03-64 \mathrm{nmol} / \mathrm{l} ; \mathrm{ng} / \mathrm{ml} * 3.18)$.

\section{Statistical analysis}

Descriptive analyses were performed using SPSS Version 19 and Microsoft Excel 2010 (Redmond, WA, USA). Baseline variables are presented as median and interquartile (IQR) ranges as in the majority a normal distribution was not present. Correlation analysis was carried out using Spearman's $\rho$ and differences between groups were assessed using the non-parametric Mann-Whitney test. Linear regression analysis was performed to assess the relationship between classic and backdoor pathway metabolites.

Hormonal profiles were analyzed to detect the presence of circadian rhythms using Matlab Version 8.2 (Mathworks, Natick, MA, USA). We initially took an exploratory approach, using Bayesian spectral analysis $(15,16)$ and, by assuming a harmonic relationship between frequency components, examined the data for evidence of a circadian fundamental frequency and the presence of individual components. This allowed us to detect a circadian rhythm, and estimate the period and number of harmonics. Hormonal data were log-transformed due to the lack of normality. A cosine curve (cosinor model), a mathematicalstatistical regression technique used in chronobiological analyses of circadian rhythms (17), was then fitted to the averaged log-converted $(\ln )$ 24-h data for each hormone found to have a circadian rhythm. By fitting in a cosinor model, we were able to both confirm statistical significance of the rhythm and derive $r^{2}$, the percentage of the variance that can be explained by the model $(17,18)$. By using a $P$ value of statistical significance one rejects or accepts the hypothesis that the amplitude is zero and a significant $P$ value ascertains a significant rhythm is present.

To demonstrate circadian changes, we also designed concentration-time profiles for each hormone for patients on either dexamethasone or prednisone using geometric mean (s.E.M.) at each time point. We then measured 8- and 24-h hormonal exposure which we defined by a PK approach (WinNonlin Professional V5.2.1 Software, Certara USA, Princeton, NJ, USA). The parameters included geometric mean (10th to 90th percentiles) 8-hourly/24-hourly AUC (2300-0700 h; 0700-1500 h; 1500-2300 h, 2300-2300 h). To reduce heterogeneity, one patient receiving morning dexamethasone was evaluated separately. Two-tailed tests were performed and $P$ value $<0.05$ was considered statistically significant.

Defining hormonal monitoring times $\boldsymbol{\wedge}$ Circadian hormonal profiles provided robust measurements to help define optimal monitoring time ranges dependent on type and time of glucocorticoid administration. Two time parameters were used: i) $T_{\min } \mathrm{AC}$, the number of hours from dose administration to the lowest adrenocortical (AC) hormone level; ii) $T_{\max } \mathrm{AC}$, the number of hours from dose administration to the maximal AC hormone level reached after the hormone escaped control. In some patients in whom hormone levels were above target ranges prior to dose administration and remained above these defined ranges after dosing, that is, control was not achieved, $T_{\max } \mathrm{AC}$ was taken as the maximal concentration subsequent to a drop in hormone levels post dose administration. For individual variables, hormonal control was defined as: ACTH 1.1-15.2 pmol/l (1.5 the upper limit of normal range), 17OHP $1.5-36 \mathrm{nmol} / 1(7,19)$ and normal range for androstenedione $0.6-6.1 \mathrm{nmol} / \mathrm{l}$, androsterone $0.7-2.8 \mathrm{nmol} / \mathrm{l}$, DHEA $0.8-20.8 \mathrm{nmol} / \mathrm{l}$, testosterone (males 3.5-25.7 nmol/l, females $0.3-2.5 \mathrm{nmol} / \mathrm{l}$ ) and progesterone (males $0.03-0.2 \mathrm{nmol} / \mathrm{l}$, females 0.03 to $-64 \mathrm{nmol} / \mathrm{l})$. Overall disease control was based on androstenedione being within the normal range. Hormonal concentrations for routinely measured hormones at $T_{\min } \mathrm{AC}$ and $T_{\max } \mathrm{AC}$ were recorded.

\section{Results}

Sixteen adult patients (six women) with classic CAH participated, with median (IQR) age 23 (20-42) years, weight 70.9 (57.5-95.4) $\mathrm{kg}$ and BMI 25.9 (22.5-32.5) $\mathrm{kg} / \mathrm{m}^{2}$. Based on early morning $0700 \mathrm{~h}$ androstenedione, 8 (50\%) patients were in poor disease control 29 (s.D. 28) $\mathrm{nmol} / \mathrm{l}$. In males $n=3$, the androstenedione concentration was 42 (s.D. 37) nmol/l while in females $n=5$, this was 21 (s.D. 21) nmol/l. Eight patients had acceptable adrenal hormone levels 4 (s.D. 2) $\mathrm{nmol} / \mathrm{In}$ males $n=7$, the androstenedione concentration was 4 (s.D. 2) nmol/l while in females $n=1$, this was $4 \mathrm{nmol} / \mathrm{l}$. Based on 
$1700 \mathrm{~h}$ levels 10 (62.5\%) patients had elevated androstenedione (17 (s.D. 12) nmol/l; males $n=4,19$ (s.D. 9) nmol/l; females $n=6,16$ (s.D. 14) nmol/l) (Supplementary Table 1, see section on supplementary data given at the end of this article). Eleven patients were on prednisone twice daily at median (10th to 90th percentiles) $0800 \mathrm{~h}$ (0700-1000 h) and $2100 \mathrm{~h}(1900-2300 \mathrm{~h})$ whereas four patients were taking dexamethasone in the evening at a median (10th to 90th percentiles) time of $2200 \mathrm{~h}$ (2118-2242 h). One patient taking dexamethasone $0.375 \mathrm{mg}$ in the morning at $0800 \mathrm{~h}$ had normal hormonal control throughout most of the $24 \mathrm{~h}$.

\section{Circadian rhythm analysis}

All hormones except DHEA displayed evidence of circadian rhythm with remarkable consistency given the small sample size and inter-individual variation (Supplementary Table 1, see section on supplementary data given at the end of this article). A cosinor model, fitted to the averaged $24 \mathrm{~h}$ data of all patients, resulted in a significant sinusoidal curve for ACTH $\left(r^{2}, 0.95 ; P<0.001\right)$ (two harmonics) and 17OHP $\left(r^{2}, 0.70 ; P=0.003\right)$, androstenedione $\left(r^{2}, 0.47 ; P=0.043\right)$, androsterone $\left(r^{2}, 0.80 ; P<0.001\right)$, testosterone $\left(r^{2}, 0.47\right.$; $P=0.042)$ and progesterone $\left(r^{2}, 0.64 ; P=0.006\right)$ (all one harmonic). The presence of a rhythm was not related to gender or type of glucocorticoid. To support these findings, 8-hourly hormonal AUCs indicate higher hormonal exposure in the morning and early afternoon with decreasing levels thereafter (Table 1). Androsterone showed higher $1700 \mathrm{~h}$ than $0700 \mathrm{~h}$ levels (IQR) (Supplementary Table 1 , see section on supplementary data given at the end of this article) suggesting an inverted rhythm but this was not confirmed when estimating 8 hourly AUCs (Table 1). Concentration-time profiles for all hormones revealed variable hormonal responses to drug levels (Fig. 2).

\section{Establishing hormonal monitoring times}

For patients on prednisone, the time to the lowest and peak hormone concentrations following morning and evening doses was remarkably similar across the majority of adrenocortical hormones (Table 2). Maximal levels occurred approximately $10 \mathrm{~h}$ following dose, while the lowest values occurred approximately $4-5 \mathrm{~h}$ following dose. Time for measurement of peak $17 \mathrm{O} \mathrm{HP}$ and androstenedione, the typical biomarkers of disease control, best corresponded to (mean (s.D.) $T_{\max } \mathrm{AC} 9.7$ (3.5) h) after the morning dose and (mean (s.D.) $T_{\max } \mathrm{AC} 10.3$ (2.4) h) for the evening dose, whereas monitoring for hormonal suppression corresponded to (mean (s.D.) $T_{\min } \mathrm{AC} 4.3$ $(2.3) \mathrm{h}$ ) for the morning dose and (mean (s.D.) $T_{\min } \mathrm{AC}$ $4.5(2.0) \mathrm{h})$ for the evening dose. In support of these findings, these time-points correlated $(P<0.001)$ with pre and post 8-hourly AUCs (data not shown). In a subanalysis, exploring whether $T_{\max } \mathrm{AC}$ and $T_{\min } \mathrm{AC}$ in patients on prednisone varied in the different sexes these were in general similar with no significant differences (Supplementary Table 2, see section on supplementary data given at the end of this article).

The time to lowest hormone concentrations and time to peak levels varied across the different adrenocortical hormones with once daily dexamethasone (Table 3). Time for measurement of 17OHP and androstenedione best corresponded to (mean (s.D.) $T_{\min } \mathrm{AC} 9.2(3.5) \mathrm{h}$ ) and (mean (s.D.) $T_{\max } \mathrm{AC} 16.4$ (7.2) h) for dexamethasone.

Hormonal concentrations at these time-points $\left(T_{\min }\right.$ AC vs $T_{\text {max }} \mathrm{AC}$ ) show significant differences for $17 \mathrm{OHP}$ (median 6.4 vs $67.6 \mathrm{nmol} / \mathrm{l} ; P=0.005$ ), and androstenedione (median 4.6 vs $9.5 \mathrm{nmol} / \mathrm{l} ; P=0.046$ ) and no difference for testosterone (males median 9.3 vs $11.8 \mathrm{nmol} / \mathrm{l} ; P=0.31$; females median $1.3 \mathrm{vs} 1.8 \mathrm{nmol} / \mathrm{l}$; $P=0.15)$.

Table 1 Twenty-four hour and $8 \mathrm{~h}$ hormonal exposure in patients with Classic CAH on treatment.

\begin{tabular}{|c|c|c|c|c|}
\hline & \multicolumn{4}{|c|}{ Geometric mean (10th to 90th percentiles) } \\
\hline & AUC $(24$ h) $(2300-2300)$ & AUC (2300-0700) & AUC (0700-1500) & AUC (1500-2300) \\
\hline ACTH (pmol/l h) & $257(38-1227)$ & $45(8-383)$ & $106(11-631)$ & $82(15-417)$ \\
\hline $170 \mathrm{HP}(\mathrm{nmol} / \mathrm{h})$ & $633(19-7113)$ & $122(5-2066)$ & $265(8-3784)$ & $199(5-1700)$ \\
\hline Androstenedione (nmol/l h) & $179(30-1081)$ & $51(11-325)$ & $65(10-453)$ & $59(9-303)$ \\
\hline Androsterone (nmol/l h) & $121(44-478)$ & $33(11-130)$ & $43(13-192)$ & $42(14-157)$ \\
\hline DHEA (nmol/l h) & $42(10-730)$ & $13(3-115)$ & $16(3-344)$ & $12(3-301)$ \\
\hline Testosterone (males) (nmol/l h) & $321(127-2037)$ & $109(23-1536)$ & $105(52-248)$ & $90(36-252)$ \\
\hline Testosterone (females) (nmol// h) & $40(22-131)$ & $12(6-41)$ & $14(7-42)$ & $14(8-47)$ \\
\hline Progesterone (males) (nmol/l h) & $17.0(1.2-543.8)$ & $4.4(0.3-197.2)$ & $6.5(0.2-286.2)$ & $4.3(0.2-184.1)$ \\
\hline Progesterone (females) (nmol// h) & $58.8(13.4-1329.2)$ & $6.6(0.2-321.2)$ & $23.2(2.3-537.4)$ & $22.2(6.4-470.6)$ \\
\hline
\end{tabular}

AUC, area under the curve. 

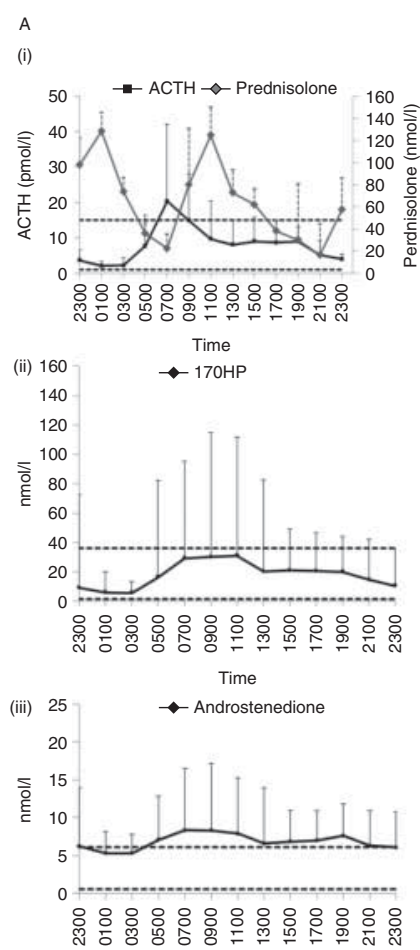

Time
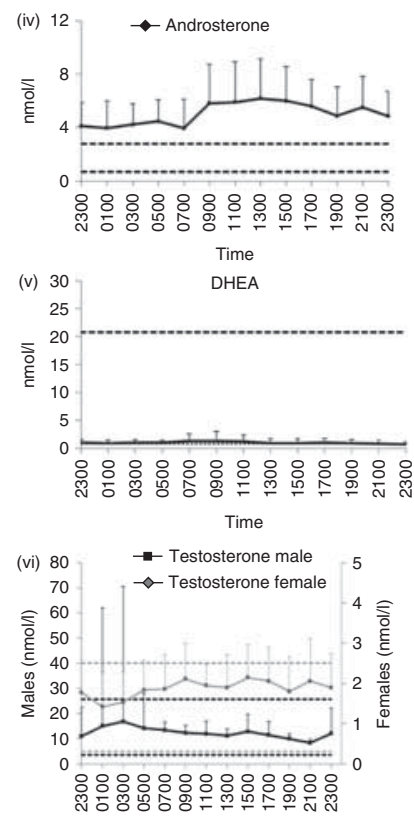

Time

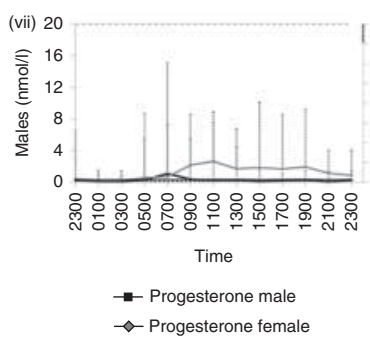

B
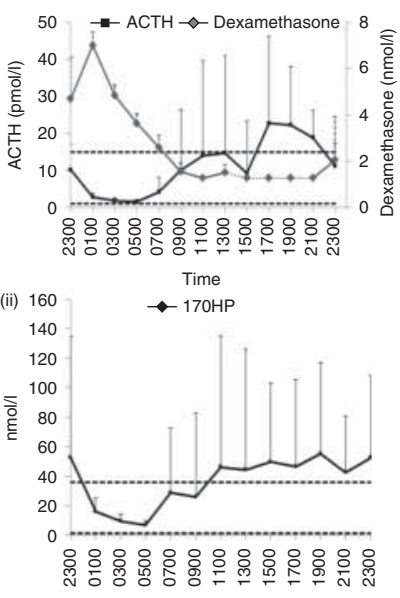

Time

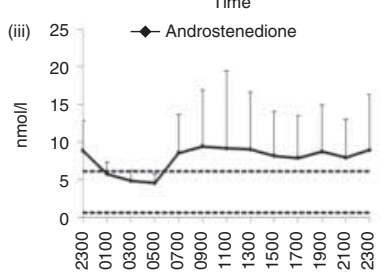

Time
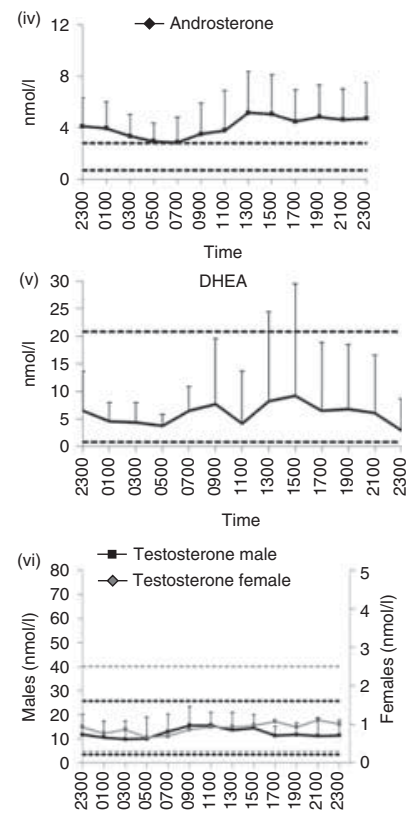

Time

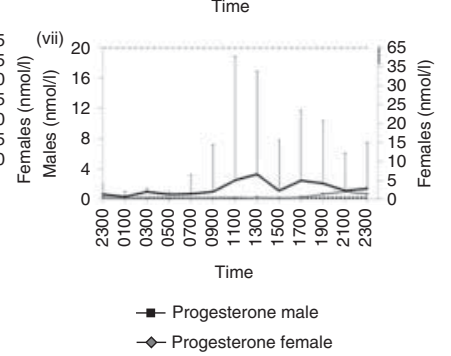

\section{Exploring hormonal inter-relationships to identify novel disease biomarkers}

One of the hormones that was analyzed in our study and is not routinely measured was progesterone. $\mathrm{AUC}_{(0-24 \mathrm{~h})}$ progesterone significantly correlated with ACTH and $17 \mathrm{OHP}$ in both males and females, whereas in males these relationships were stronger and progesterone was also associated with androstenedione (Table 4, Supplementary Figure 1, see section on supplementary data given at the end of this article). Progesterone $\mathrm{AUC}_{0-24 \mathrm{~h}}$ significantly correlated with backdoor metabolites (pdiol: females, $\rho=0.83, P=0.042$; males, $\rho=0.87, P=0.002$; serum androsterone $\mathrm{AUC}_{0-24 \mathrm{~h}}$ : females, $\rho=1.0, P=0.01$; males, $\rho=0.714, P=0.047$ ). DHEA showed no relationship with ACTH, 17OHP, androstenedione or any of the measured backdoor metabolites. Overall, $47 \%$ of patients had undetectable DHEA levels throughout the $24 \mathrm{~h}$.

Twenty-four hour urine pdiol, a backdoor pathway metabolite, serum androsterone, a product of both classic and backdoor pathways, and $5 \beta$-pdiol, a precursor of pregnanetriol, were significantly correlated with ACTH, 17OHP and androstenedione (Fig. 3a, Table 4). Twentyfour hour urine pdiol (Median: 1848 vs $150 \mathrm{nmol} / 24 \mathrm{~h}$; $P=0.004$ ), $5 \beta$-pdiol (Median: 20481 vs $2643 \mathrm{nmol} / 24 \mathrm{~h}$; $P=0.011$ ) and androsterone $\mathrm{AUC}_{0-24 \mathrm{~h}}$ (median: 229 vs $75 \mathrm{nmol} / \mathrm{l} ; P=0.039$ ) were significantly higher in patients with poor disease control (Fig. 3b). Pdiol positively predicted androstenedione (unstandardized coefficient $B=0.4595 \%$ CI 0.22 to $0.68 ; P=0.001)$ and $17 \mathrm{OHP}$

\section{Figure 2}

Serum hormonal profiles for exogenous glucocorticoids and CAH-related hormones. (A) Eleven patients (six males; five females) receiving twice daily prednisone experienced hormonal escape mainly in the early morning for ACTH, androstenedione, androsterone and progesterone (males). 17OHP levels were higher in the morning but mainly remained within the desired range. In some patients, a spontaneous reduction in hormone levels occurs before the evening dose. (B) Four patients (three males; one female) receiving nocturnal dexamethasone had escape of most hormones including ACTH, 17OHP, androstenedione, androsterone and progesterone in the afternoon. Dotted segment of dexamethasone concentration-time profile (between 1300 and $2100 \mathrm{~h}$ ) represents undetectable levels. Geometric mean (s.E.M.) is shown for prednisolone and dexamethasone and all other hormones. Horizontal dotted lines indicate normal ranges or optimal hormonal control. Only one female was taking dexamethasone. 
Table 2 Target monitoring times following twice daily prednisone in 11 patients with classic $\mathrm{CAH}$. Prednisone (dose Range - HC equiv: $12 \mathrm{mg} / \mathrm{m}^{2}$ per day $-33.7 \mathrm{mg} / \mathrm{m}^{2}$ perday).

\begin{tabular}{|c|c|c|c|c|}
\hline \multirow[b]{2}{*}{ Hormones } & \multicolumn{2}{|c|}{ Morning dose } & \multicolumn{2}{|c|}{ Evening dose } \\
\hline & $T_{\min } \mathrm{AC}(\mathrm{h})^{\mathrm{a}}$ & $T_{\max } \mathrm{AC}(\mathrm{h})^{\mathrm{a}}$ & $T_{\min } \mathrm{AC}(\mathrm{h})^{\mathrm{a}}$ & $T_{\max } \mathrm{AC}(\mathrm{h})^{\mathrm{c}}$ \\
\hline ACTH & $4.5(1.3)$ & $11.0(2.5)$ & $3.2(1.5)$ & $10.9(2.0)$ \\
\hline 17OHP & $4.7(2.4)$ & $9.7(3.5)$ & $4.9(1.8)$ & $10.7(2.0)$ \\
\hline Androstenedione & $3.8(2.2)$ & $9.6(3.6)$ & $4.1(2.1)$ & $10.0(2.8)$ \\
\hline Androsterone & $7.4(3.1)$ & $10.2(3.2)$ & $4.2(2.6)$ & $8.2(3.5)$ \\
\hline DHEA & $3.4(4.1)$ & $12.7(1.6)$ & $2.5(3.8)$ & $10.1(2.2)$ \\
\hline Testosterone & $6.0(4.4)$ & $11.5(2.7)$ & $3.8(1.3)$ & $11.0(1.5)$ \\
\hline Progesterone & $4.0(1.9)$ & $10.2(3.3)$ & $4.0(2.5)$ & $11.2(2.0)$ \\
\hline
\end{tabular}

$T_{\min } \mathrm{AC}$, the number of hours from dose administration to minimal adrenocortical (AC) hormone level; $T_{\max } \mathrm{AC}$, the number of hours from dose administration to the maximal AC hormone level. ${ }^{\mathrm{a}}$ Mean (s.D.)

(unstandardized coefficient $B=0.8995 \%$ CI 0.63 to 1.15 ; $P<0.001)$ by linear regression.

\section{Discussion}

Our comprehensive hormonal analysis of adult patients with $\mathrm{CAH}$ reveals intact diurnal rhythms of multiple hormones and fluctuating androgen excess throughout the day that may not be detected with routine random single hormonal measurements. The androgen excess commonly experienced by patients with CAH resulted from both the classic and backdoor pathways to androgen production, albeit driven by the circadian secretion of ACTH. Twenty-four hour serial sampling allowed us to estimate when escape from hormonal suppression most commonly occurred and to evaluate this in relation to glucocorticoid administration. To our knowledge, this is the most detailed study to date evaluating optimal monitoring times in patients on intermediate and longacting glucocorticoids and the only study to also include backdoor pathway steroid metabolites.

In our study, detailed pharmacokinetic (PK) modelling revealed that maximal hormone levels in patients on morning and evening prednisone occur $10 \mathrm{~h}$ after dose administration and $16 \mathrm{~h}$ following dexamethasone. In addition, lowest levels corresponding to maximal suppression occurs around 4-5 h after prednisone and $9 \mathrm{~h}$ after a daily dexamethasone dose. Significant differences were observed between these highest and lowest levels of $17 \mathrm{OHP}$ and androstenedione, highlighting the importance of the timing of hormonal evaluation. Furthermore, we found that serum progesterone and androsterone and 24- urinary pdiol and 5 $\beta$-pdiol correlated well with routinely monitored hormones and could be alternative markers of disease control. These findings provide insight into the importance of taking into consideration the type of glucocorticoid and the time of dose administration when monitoring hormone levels and also suggest that in poorly controlled CAH patients, both the classic and backdoor pathways are similarly activated.

The management of $\mathrm{CAH}$ changes throughout life. Although, the majority of children with CAH are treated with short-acting hydrocortisone (1), a significant number of $\mathrm{CAH}$ adults are treated with longer-acting glucocorticoids such as prednisone, prednisolone or dexamethasone $(19,20)$. These medications are often used for convenience because they can be dosed once or twice daily or to optimise compliance. Long- and intermediate-acting glucocorticoids have shown better adrenocortical suppression compared to hydrocortisone $(21,22)$, although they may increase risk of metabolic complications such as insulin resistance (19) and osteoporosis (23). Our data reveal that androgen suppression may be transient even for long- and intermediate-acting glucocorticoids with wide inter-individual variability. Prednisone is an inactive synthetic analogue of cortisone, and post-absorption is rapidly converted to biologically active prednisolone by hepatic 11-beta hydroxysteroid dehydrogenase Type 1 . Although it is recognised that the biological half-life of prednisolone is approximately 18-36 $\mathrm{h}$ (24), and the serum half-life is around $3-4 \mathrm{~h}(25,26)$, the biological half-life for corticosterone suppression has been shown to be $6.2 \mathrm{~h}$ (27). Similarly, dexamethasone has a biological half-life of 36-54 h (24), a serum half-life of around $4-5 \mathrm{~h}$ and a biological half-life for corticosterone suppression of $7 \mathrm{~h}$

Table 3 Target monitoring times following once daily dexamethasone in five patients with Classic CAH. Dexamethasone (dose range - HC equiv: $9.6-21.3 \mathrm{mg} / \mathrm{m}^{2}$ per day).

\begin{tabular}{|c|c|c|}
\hline \multirow[b]{2}{*}{ Hormones } & \multicolumn{2}{|c|}{ Once daily dose } \\
\hline & $T_{\min } \mathrm{AC}(\mathrm{h})^{\mathrm{a}}$ & $T_{\max } \mathrm{AC}(\mathrm{h})^{1}$ \\
\hline ACTH & $5.8(1.9)$ & $20.2(4.4)$ \\
\hline $170 \mathrm{HP}$ & $9.4(1.8)$ & $17.4(6.5)$ \\
\hline Androstenedione & $9.0(4.8)$ & $15.4(8.4)$ \\
\hline Androsterone & $6.2(2.2)$ & $17.4(8.7)$ \\
\hline DHEA & $3.4(2.9)$ & $21.4(3.6)$ \\
\hline Testosterone & $3.8(2.4)$ & $20.6(7.6)$ \\
\hline Progesterone & $6.2(1.9)$ & $11.8(7.6)$ \\
\hline
\end{tabular}

$T_{\min } \mathrm{AC}$, the number of hours from dose administration to minimal adrenocortical (AC) hormone level; $T_{\max } A C$, the number of hours from dose administration to the maximal AC hormone level.

a Mean (s.D.). 
Table 4 Correlation between routinely measured biomarkers and other classic and backdoor pathway metabolites.

\begin{tabular}{l}
\hline Biomarkers \\
\hline Serum steroids \\
Androsterone \\
DHEA \\
Testosterone - Male \\
Testosterone - Female \\
Progesterone - Male \\
Progesterone - Female \\
Urinary Steroids \\
Pdiol \\
5 $\beta$-pdiol \\
\hline
\end{tabular}

\begin{tabular}{c}
\hline ACTH co-efficient $(P \text { value })^{a}$ \\
\hline $0.63(0.02)$ \\
-0.09 \\
-0.60 \\
$0.83(0.04)$ \\
$0.73(0.03)$ \\
$0.89(0.02)$ \\
$0.62(\leq 0.01)$ \\
$0.68(\leq 0.01)$
\end{tabular}

Correlations based on $\mathrm{AUC}_{0-24 \mathrm{~h}}$ (serum) or $24 \mathrm{~h}$ urine collection.

${ }^{a} P$ values $>0.05$ not shown.

${ }^{\mathrm{b}}$ Androsterone produced by both classic and backdoor pathways.

(27). The corticosterone suppression data from Meikle et al. (27) could explain why many of our patients on prednisone experienced maximal 17OHP and androstenedione within $10 \mathrm{~h}$ following dose administration and patients on dexamethasone within $16 \mathrm{~h}$. Dexamethasone concentrations were detected in the circulation for around $10 \mathrm{~h}$. Our data also suggest that some patients receiving once daily dexamethasone could potentially benefit from twice daily dexamethasone though this might increase the risk for adverse metabolic effects. Other studies investigating monitoring times for hydrocortisone have shown a rapid fall in 17OHP levels after the morning hydrocortisone dose and early morning laboratory evaluation is generally suggested for patients receiving hydrocortisone $(22,28)$.

In most untreated patients, $17 \mathrm{OHP}$ and sex steroids maintain their circadian rhythms (3) and the circadian rhythm of 17OHP has been shown to develop as early as 3 months of age (29). Our analysis of 24-h concentrationtime profiles for androstenedione and 17OHP indicate that patients on long-acting glucocorticoids maintain hormonal rhythms and exhibit wide hormonal fluctuations. Interestingly, irrespective of a low glucocorticoid state, in some instances there was a decrease in 17OHP and androgen levels in the evening during the quiescent phase, an effect most likely related to circadian regulation of the endogenous timing system by the central clock in the suprachiasmatic nucleus. Thus, hormonal disturbances may only be appreciated when measuring multiple hormone samples during the day. Unfortunately, this type of research-based analysis may be too intensive, laborious and costly to be carried out as part of daily clinical management. To circumvent this problem, we attempted to define the most suitable time to measure hormone levels related to poor disease control, this dependent on time of dose and glucocorticoid formulation. This may be an alternative strategy especially as some clinicians do measure adrenal androgens during other times of the day such as late in the afternoon (30). Our opinion is that aiming to measure maximal hormone levels is most useful in clinical management, corresponding to evaluation in the early morning for night time prednisone, or late afternoon for morning prednisone or night time dexamethasone. We also emphasize that hormone levels taken at recommended time points should not preclude a full clinical assessment of the patient. Management decisions should take all clinical features and biochemical data into consideration.

Comprehensive steroid panels were evaluated. DHEA was mostly suppressed or within normal range even when disease was uncontrolled, confirming that DHEA is not a useful biomarker in CAH. In addition, DHEA levels did not correlate with any of the other measured hormones. Low DHEA has previously been described in patients with classic CAH $(31,32)$. Our data support the notion that DHEA is not solely regulated by ACTH in CAH patients, but low levels may be due to abnormal adrenal gland development as patients with 21-hydroxylase deficiency have been shown to have lack of zonation with extensive intermingling of adrenocortical and adrenomedullary cells $(7,33)$. Low intra-adrenal cortisol in $\mathrm{CAH}$ patients also may result in low DHEA production $(31,34)$.

Conversely, progesterone may be useful in the management of $\mathrm{CAH}$. In $\mathrm{CAH}$, an increase in ACTH stimulation presumably drives the production of progesterone. This is supported by the significant correlation between progesterone and ACTH in our study. Much is unknown 

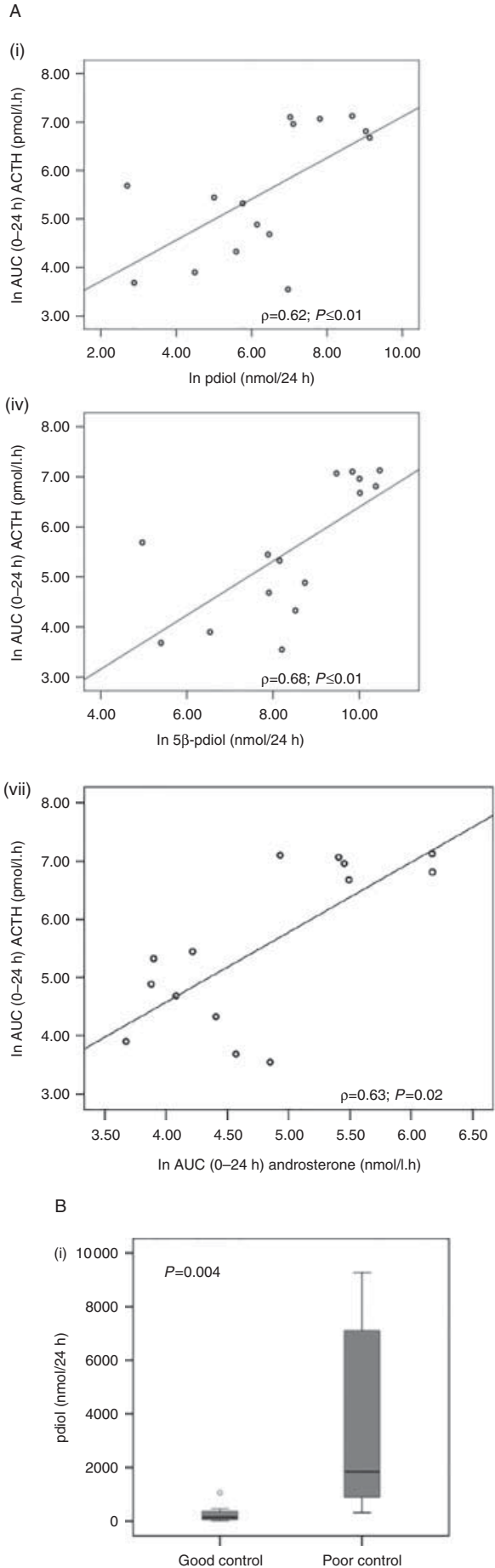
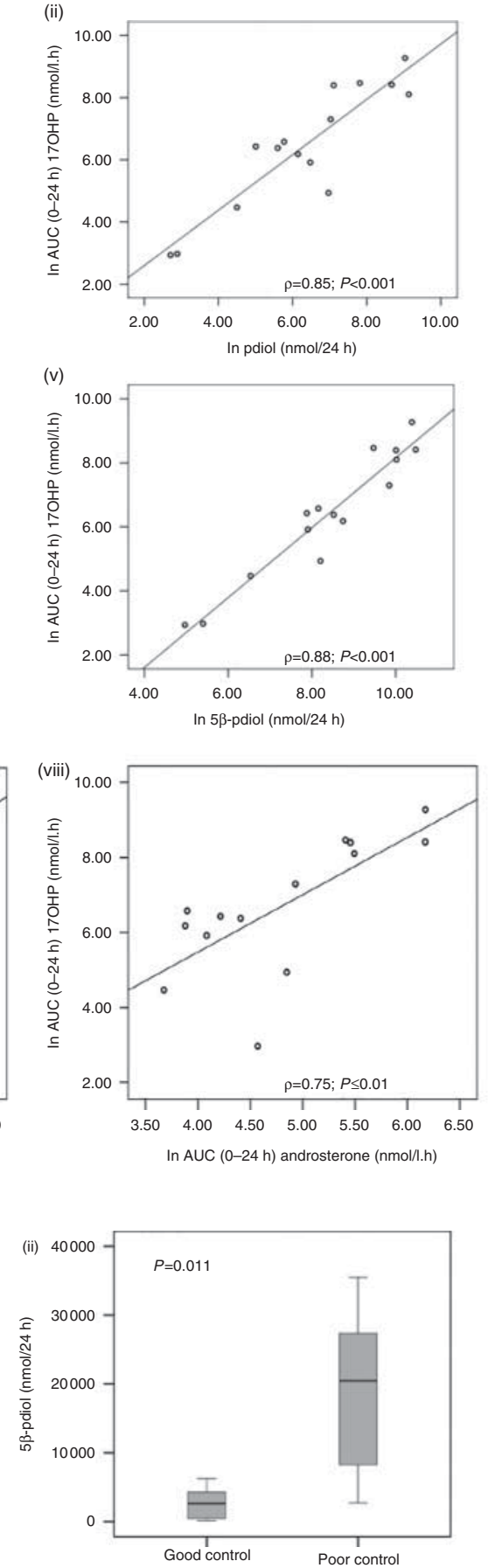
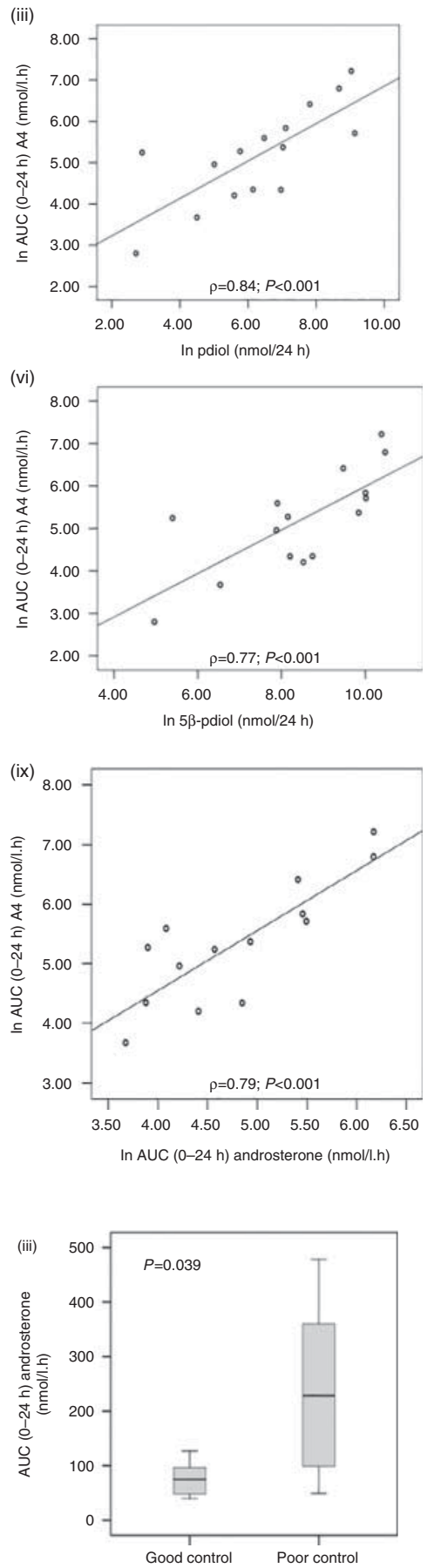

\section{Figure 3}

(A) Hormonal inter-relationships for pdiol, 5 $\beta$-pdiol and androsterone. Correlations between backdoor pathway $24 \mathrm{~h}$

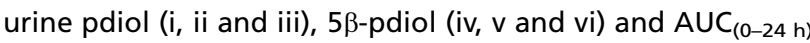
androsterone (vii, viii and $\mathrm{ix}$ ) with major serum biomarkers.

(B) Pdiol, 5 $\beta$-pdiol and androsterone levels in $\mathrm{CAH}$. Box and 
about progesterone in $\mathrm{CAH}$. However, high progesterone levels could contribute to female infertility (35). In a casecontrol study of 16 women with classic $\mathrm{CAH}$, those patients with a low LH pulse amplitude and frequency had higher progesterone levels and worse hormonal control than those with LH pulsatility similar to normal controls (36). Further studies investigating the relevance of high progesterone in $\mathrm{CAH}$ and its impact on fertility are needed.

An intriguing alternative pathway to androgen production is the backdoor pathway, which produces the most potent androgen, dihydrotestosterone (DHT), without the intermediary androstenedione or testosterone $(11,37)$. Kamrath et al. (11) found that androgen biosynthesis via the backdoor pathway is active throughout postnatal life, with possibly less backdoor pathway contribution to androgenic steroid production post adrenarche (38). Prior studies suggest that backdoor pathway androgen production increases in adults with $\mathrm{CAH}$ as control of androgen excess deteriorates (39). We mostly found a proportional increase in classic and backdoor pathway metabolites in adults as disease control deteriorates, albeit in a small sample size. The relationship between clinical features and backdoor pathway metabolites, together with the use of these hormones as markers of disease status, requires further investigation.

Limiting factors in our study include the use of different doses of glucocorticoids that were administered at different times. Furthermore, a small number of patients were on dexamethasone. With regards to identifying minimal hormone levels or more specifically the maximal suppression following medication $\left(T_{\min } \mathrm{AC}\right)$, we did not account for the clock-induced physiological drop in hormones, and this should be considered. In addition, $T_{\min } \mathrm{AC}$ after evening prednisone suggests monitoring during very early morning which would be impractical in clinical practice though possibly useful to investigators in the research setting.

Our study is unique in that we obtained detailed $24 \mathrm{~h}$ circadian profiles of common and uncommon biomarkers of androgen excess in patients with classic $\mathrm{CAH}$ allowing us to approximate ideal monitoring times post dose administration. Achieving optimal metabolic control is difficult in $\mathrm{CAH}$ and we found that laboratory evaluation is best performed in relation to medication timing. Backdoor pathway metabolites and progesterone are alternative biomarkers of disease control and may be useful in the management of $\mathrm{CAH}$ patients. Future studies should investigate the association between these steroids and clinical features of hyperandrogenism. Our findings provide useful information regarding the management of the adult patient with $\mathrm{CAH}$ and thus may help guide future clinical practice.
Supplementary data

This is linked to the online version of the paper at http://dx.doi.org/10.1530/ EJE-15-0064.

Declaration of interest

D $\mathrm{P}$ Merke received research funds from Diurnal Ltd through $\mathrm{NIH}$ Cooperative Research and Development Agreement. R J Ross is Director of Diurnal Ltd.

\section{Funding}

This research was supported in part by the Intramural Research Program of the NIH and in part by Diurnal Ltd.

\section{Acknowledgements}

We thank our patients for participating in the study, our nursing staff of the 5SWN Metabolic Unit for their assistance in carrying out this study and their expertise in serial sampling, and the CARES Foundation for patient referrals.

\section{References}

1 Speiser PW, Azziz R, Baskin LS, Ghizzoni L, Hensle TW, Merke DP, Meyer-Bahlburg HF, Miller WL, Montori VM, Oberfield SE et al. Congenital adrenal hyperplasia due to steroid 21-hydroxylase deficiency: an Endocrine Society clinical practice guideline. Journal of Clinical Endocrinology and Metabolism 201095 4133-4160. (doi:10.1210/jc.2009-2631)

2 Veldhuis JD, Iranmanesh A, Johnson ML \& Lizarralde G. Amplitude, but not frequency, modulation of adrenocorticotropin secretory bursts gives rise to the nyctohemeral rhythm of the corticotropic axis in man. Journal of Clinical Endocrinology and Metabolism 199071 452-463. (doi:10.1210/jcem-71-2-452)

3 Frisch H, Parth K, Schober E \& Swoboda W. Circadian patterns of plasma cortisol, 17-hydroxyprogesterone, and testosterone in congenital adrenal hyperplasia. Archives of Disease in Childhood 198156 208-213. (doi:10.1136/adc.56.3.208)

4 Young MC, Robinson JA, Read GF, Riad-Fahmy D \& Hughes IA. 170Hprogesterone rhythms in congenital adrenal hyperplasia. Archives of Disease in Childhood 198863 617-623. (doi:10.1136/adc.63.6.617)

5 Hughes IA \& Read GF. Control in congenital adrenal hyperplasia monitored by frequent saliva $17 \mathrm{OH}$-progesterone measurements. Hormone Research 198419 77-85. (doi:10.1159/000179870)

6 Auchus RJ \& Arlt W. Approach to the patient: the adult with congenital adrenal hyperplasia. Journal of Clinical Endocrinology and Metabolism 201398 2645-2655. (doi:10.1210/jc.2013-1440)

7 Merke DP \& Bornstein SR. Congenital adrenal hyperplasia. Lancet 2005 365 2125-2136. (doi:10.1016/S0140-6736(05)66736-0)

8 Groschl M, Rauh M \& Dorr HG. Cortisol and 17-hydroxyprogesterone kinetics in saliva after oral administration of hydrocortisone in children and young adolescents with congenital adrenal hyperplasia due to 21-hydroxylase deficiency. Journal of Clinical Endocrinology and Metabolism 200287 1200-1204. (doi:10.1210/jcem.87.3.8297)

9 Young MC, Cook N, Read GF \& Hughes IA. The pharmacokinetics of low-dose dexamethasone in congenital adrenal hyperplasia. European Journal of Clinical Pharmacology 198937 75-77.

10 Fuqua JS, Rotenstein D \& Lee PA. Duration of suppression of adrenal steroids after glucocorticoid administration. International Journal of Pediatric Endocrinology 20102010 712549. (doi:10.1186/1687-98562010-712549) 
11 Kamrath C, Hochberg Z, Hartmann MF, Remer T \& Wudy SA. Increased activation of the alternative "backdoor" pathway in patients with 21-hydroxylase deficiency: evidence from urinary steroid hormone analysis. Journal of Clinical Endocrinology and Metabolism 201297 E367-E375. (doi:10.1210/jc.2011-1997)

12 Finkielstain GP, Chen W, Mehta SP, Fujimura FK, Hanna RM, Van Ryzin C, McDonnell NB \& Merke DP. Comprehensive genetic analysis of 182 unrelated families with congenital adrenal hyperplasia due to 21-hydroxylase deficiency. Journal of Clinical Endocrinology and Metabolism 201196 E161-E172. (doi:10.1210/jc.2010-0319)

13 Guo T, Taylor RL, Singh RJ \& Soldin SJ. Simultaneous determination of 12 steroids by isotope dilution liquid chromatography-photospray ionization tandem mass spectrometry. Clinica Chimica Acta 2006372 76-82. (doi:10.1016/j.cca.2006.03.034)

14 Stolze BGV, Gu J \& Soldin SJ. A408 Development and Validation of a High Performance Liquid Chromatography Tandem Mass Spectrometry 9 Steroid Panel using Minimal Sample Volume. AACC Annual meeting Abstracts, 2014 S133.

15 Hansen LK, Nielsen FA \& Larsen J. Exploring fMRI data for periodic signal components. Artificial Intelligence in Medicine 200225 35-44. (doi:10.1016/S0933-3657(02)00007-6)

16 Bretthorst GL. Bayesian spectrum analysis and parameter estimation. Lecture Notes in Statistics. Berlin: Springer-Verlag, 1988.

17 Cornelissen G. Cosinor-based rhythmometry. Theoretical Biology \& Medical Modelling 201411 16. (doi:10.1186/1742-4682-11-16)

18 Cugini P. Chronobiology: principles and methods. Annali dell'Istituto Superiore di Sanità 199329 483-500.

19 Finkielstain GP, Kim MS, Sinaii N, Nishitani M, Van Ryzin C, Hill SC, Reynolds JC, Hanna RM \& Merke DP. Clinical characteristics of a cohort of 244 patients with congenital adrenal hyperplasia. Journal of Clinical Endocrinology and Metabolism 201297 4429-4438. (doi:10.1210/jc. 2012-2102)

20 Arlt W, Willis DS, Wild SH, Krone N, Doherty EJ, Hahner S, Han TS, Carroll PV, Conway GS, Rees DA et al. Health status of adults with congenital adrenal hyperplasia: a cohort study of 203 patients. Journal of Clinical Endocrinology and Metabolism 201095 5110-5121. (doi:10.1210/jc.2010-0917)

21 Horrocks PM \& London DR. A comparison of three glucocorticoid suppressive regimes in adults with congenital adrenal hyperplasia. Clinical Endocrinology 198217 547-556. (doi:10.1111/j.1365-2265. 1982.tb01613.x)

22 Dauber A, Feldman HA \& Majzoub JA. Nocturnal dexamethasone versus hydrocortisone for the treatment of children with congenital adrenal hyperplasia. International Journal of Pediatric Endocrinology 2010 2010 347636. (doi:10.1186/1687-9856-2010-347636)

23 Falhammar H, Filipsson Nystrom H, Wedell A, Brismar K \& Thoren M. Bone mineral density, bone markers, and fractures in adult males with congenital adrenal hyperplasia. European Journal of Endocrinology 2013 168 331-341. (doi:10.1530/EJE-12-0865)

24 Repchinsky C. Compendium of Pharmaceuticals and Specialties. The Canadian Drug Reference for Health Professionals 2008 Ottawa N Canadian pharmacists Association 2008 Corticosteroids pg 574 to 576.

25 Meikle AW, Weed JA \& Tyler FH. Kinetics and interconversion of prednisolone and prednisone studied with new radioimmunogassays. Journal of Clinical Endocrinology and Metabolism 197541 717-721. (doi:10.1210/jcem-41-4-717)
26 Disanto AR \& Desante KA. Bioavailability and pharmacokinetics of prednisone in humans. Journal of Pharmaceutical Sciences 197564 109-112. (doi:10.1002/jps.2600640122)

27 Meikle AW \& Tyler FH. Potency and duration of action of glucocorticoids. Effects of hydrocortisone, prednisone and dexamethasone on human pituitary-adrenal function. American Journal of Medicine 197763 200-207. (doi:10.1016/0002-9343(77)90233-9)

28 Charmandari E, Matthews DR, Johnston A, Brook CG \& Hindmarsh PC. Serum cortisol and 17-hydroxyprogesterone interrelation in classic 21-hydroxylase deficiency: is current replacement therapy satisfactory? Journal of Clinical Endocrinology and Metabolism 200186 4679-4685. (doi:10.1210/jcem.86.10.7972)

29 Solyom J. Diurnal variation in blood 17-hydroxyprogesterone concentrations in untreated congenital adrenal hyperplasia. Archives of Disease in Childhood 198459 743-747. (doi:10.1136/adc.59.8.743)

30 Rivkees SA. Dexamethasone therapy of congenital adrenal hyperplasia and the myth of the "growth toxic" glucocorticoid. International Journal of Pediatric Endocrinology 20102010569680.

31 Volkl TM, Ohl L, Rauh M, Schofl C \& Dorr HG. Adrenarche and puberty in children with classic congenital adrenal hyperplasia due to 21-hydroxylase deficiency. Hormone Research in Paediatrics 201176 400-410. (doi:10.1159/000333696)

32 El-Maouche D, Collier S, Prasad M, Reynolds JC \& Merke DP. Cortical bone mineral density in patients with congenital adrenal hyperplasia due to 21-hydroxylase deficiency. Clinical Endocrinology 201582 330-337. (doi:10.1111/cen.12507)

33 Merke DP, Chrousos GP, Eisenhofer G, Weise M, Keil MF, Rogol AD, Van Wyk JJ \& Bornstein SR. Adrenomedullary dysplasia and hypofunction in patients with classic 21-hydroxylase deficiency. New England Journal of Medicine 2000343 1362-1368. (doi:10.1056/ NEJM200011093431903)

34 Topor LS, Asai M, Dunn J \& Majzoub JA. Cortisol stimulates secretion of dehydroepiandrosterone in human adrenocortical cells through inhibition of 3ßHSD2. Journal of Clinical Endocrinology and Metabolism 201196 E31-E39. (doi:10.1210/jc.2010-0692)

35 Witchel SF \& Azziz R. Nonclassic congenital adrenal hyperplasia. International Journal of Pediatric Endocrinology 20102010625105. (doi:10.1186/1687-9856-2010-625105)

36 Bachelot A, Chakhtoura Z, Plu-Bureau G, Coudert M, Coussieu C, Badachi Y, Dulon J, Charbit B \& Touraine P. Influence of hormonal control on LH pulsatility and secretion in women with classical congenital adrenal hyperplasia. European Journal of Endocrinology 2012 167 499-505. (doi:10.1530/EJE-12-0454)

37 Auchus RJ. The backdoor pathway to dihydrotestosterone. Trends in Endocrinology and Metabolism 200415 432-438. (doi:10.1016/S10432760(04)00214-0)

38 Kamrath C, Hartmann MF \& Wudy SA. Androgen synthesis in patients with congenital adrenal hyperplasia due to 21-hydroxylase deficiency. Hormone and Metabolic Research 201345 86-91. (doi:10.1055/s-00321331751)

39 Auchus RJ, Buschur EO, Chang AY, Hammer GD, Ramm C, Madrigal D, Wang G, Gonzalez M, Steven Xu X, Smit JW et al. Abiraterone Acetate to lower androgens in women with classic 21-hydroxylase deficiency. Journal of Clinical Endocrinology and Metabolism 201499 2763-2770. (doi:10.1210/jc.2014-1258)

Received 17 January 2015

Revised version received 11 August 2015

Accepted 4 September 2015 